\title{
Psychodynamic lessons in risk assessment and management ${ }^{1}$
}

\section{Ronald Doctor}

\begin{abstract}
Risk assessment is notoriously difficult and offers a particular challenge to mental health workers. There are two main conceptual approaches to the consideration of risk assessment and management: the actuarial and the clinical methods. I use case material to examine the clinical, and in particular the psychodynamic, approach in order to illustrate that violent behaviour has meaning. Understanding its meaning and learning from it can substantially reduce the risks of further violent behaviour. Managing risk with the aid of psychodynamic psychotherapy enables the patient to become aware of his or her own mind and its function. Although this process may initially be distressing to the patient, in the longer term the aim is to enable the development of a healthier, more stable internal reality. This should, in turn, reduce the risk of dangerous acting out.
\end{abstract}

The prediction of violence is notoriously unreliable, and it offers a particular challenge to mental health workers because it involves real danger. There are two main conceptual approaches to the consideration of risk assessment - the actuarial or mathematical and the clinical (Buchanan, 1999).

The actuarial approach involves the collection of facts about the patient, including demographic data, history (specifically, previous episodes of violence) and current presentation. These facts are then weighted according to some formula and a figure is arrived at that gives a predictive value to the likelihood of a future act of violence. The problem with such an approach is that many of the 'facts' that should be part of this process are not really facts but are actually subjective and individual clinical judgements. For instance, how does one grade or rate the presence, severity and content of a delusion? Does it make a difference if such a delusion is part of a systematised set of delusional beliefs? How systematised does it have to be?

It is unlikely that such psychopathology is quantifiable except in very crude terms, and it has been argued by a number of researchers, including Mullen (1999), Dolan \& Doyle (2000), Farnham \& James (2001) and Buchanan \& Leese (2001), that the

1. For invited commentaries on this article see Holloway (2004, this issue: pp. 273-274) and Witteman (2004, this issue: pp. 275-276). actuarial model of risk assessment based on epidemiology has failed. The most reliable risk assessment remains that based essentially on the individual at the clinical level, and it requires a clear conceptual framework for containing potentially dangerous and unpredictable acting-out behaviour by patients and severe anxiety in staff working with them.

The clinical approach, and in particular psychodynamic methods, focuses on the depth and breadth of the clinical experience itself: entering into the inner world of patients and their object relationships, meeting and facing feelings as they emerge within the microcosm of the transference and the countertransference. According to psychodynamic theory, the predictive actuarial approach can be seen as a defence against coming into real contact with violent patients.

In this article I hope to show that the psychodynamic approach can make an important contribution to understanding violence (Table 1) and patients who are violent. Psychodynamics provides a unique opportunity for therapist and patient to discover and to explore the violence, both conscious and unconscious, within a safe environment. However, this is a demanding option and it involves risk on various levels. Obviously, workers do not want to be physically hurt, but there are also emotional risks. Being in the presence of a violent patient induces enormous anxiety and our thinking

Ronald Doctor is a consultant psychiatrist in psychotherapy for the West London Mental Health NHS Trust (Lakeside Mental Health Unit, West Middlesex Hospital, Twickenham Road, Isleworth TW7 6AF, UK. E-mail: ronald.doctor@wlmht.nhs.uk), of which he is Clinical Director. In addition, he is a College tutor for the Charing Cross Psychiatric Training Scheme and Programme Training Director for the West London Higher Training Scheme in Psychotherapy. He trained at the Tavistock and Portman NHS Trust and is a member of the British Psychoanalytical Society. He was formerly a visiting psychiatrist at HM Prison Wormwood Scrubs and Supervisor and Examiner of the Forensic Psychotherapy Course at the Portman Clinic. 


\section{Table 1 Models and factors in violence}

Models/factors
Biological factors
Psychological models
Instrumental
aggression
Cognitive model
Behavioural model
Social learning
Status
Psychodynamic models
Freud

Klein

Kohut

Winnicott

Attachment theory

Family factors

Social models

Environmental factors

Psychiatric disorders
Features

Fight or flight response

Testosterone levels

Reduced serotonin levels in

the brain

Tendency for males and young people to be violent

Individual learns to achieve ends by violence

Individual looks at world aggressively

Individual has received inconsistent, erratic parental punishment during childhood Violence is caused by peer pressure/modelling on peers Violence gives individual higher status

Initially, primary drive is frustration; later, primary drive is libido, secondary drive is aggression Annihilation anxiety Violence and aggression arise from developmental insults or deprivations

Object relations

Insecure attachment in infancy (e.g. owing to abuse, deprivation) leads to hostile relationships with others

$50 \%$ of violent offences in UK follow alcohol misuse Alcohol and illegal drugs disinhibit behaviour

Physical abuse in childhood Parental discord and violence Parental irritability, usually due to depression

Criminal, e.g. drug dealing Subcultural, e.g. Hell's Angels, pub brawls Sporting, political and industrial violence Relative poverty, inequality Comparative anthropology, e.g. Mead's studies

Frustration, reaction against provocative regime

Schizophrenia, especially of the paranoid type Hypomania and mania Organic mental disorder Personality disorder Post-traumatic stress disorder may become impaired. There is a danger that our own emotional violence when faced with a violent patient may threaten to undermine both our selfesteem and our sense of professional identity.

When dealing with patients who pose a risk to themselves and to others, accurate assessment of risk and dangerousness is vital for the safety and protection of all those involved. The psychoanalytically oriented assessment consultation represents a critical moment of choice for both patient and therapist. Within the harmonies and discords, the false starts and the emerging themes of the initial encounter is to be found, in essence, much of what is to come during the course of the treatment.

\section{Countertransference}

From a psychodynamic perspective, countertransference is an inevitable part of all patient contact. In its broadest sense it means the worker's emotional response, which stems both from the specific relationship with the particular patient and from the character and disposition of the worker. Conscious countertransference can usually be controlled and may shed useful light on aspects of the patient's personality and ways of relating.

Clearly, it remains an essential task for the clinician, having identified the risk of violence, to attempt to quantify this risk as part of a management plan. However, when the countertransference is unconscious it may give rise to well rationalised but destructive acting out by the worker. When faced with a difficult and potentially dangerous patient our instinct is to protect ourselves by retreating emotionally into what Hinshelwood (1999) calls a 'scientific attitude'. Typically, this reaction is given an objective justification, but there is a real danger that this objectification can then blind us to aspects of what is happening subjectively, both in the patient and in ourselves. This depersonalisation may be invited and encouraged by the psychotic patient's removal from the world of ordinary human rapport.

We all carry a desire within ourselves for an allembracing answer that will allow us to avoid facing indescribably difficult psychotic states of mind, and we need to monitor ourselves constantly to ensure that we are not falling for some seductively welcome rationalisation. Patients in dangerous, psychotic states of mind will tend to deny and explain away their own behaviour, and this can lead to a serious underrating by the assessor of the true level of risk.

Conversely, the patient with a severe personality disorder offers a relationship, but one too intensely suffused with human feelings that are usually very unpleasant. These patients make us feel manipulated, as though we are impelled to conform to a pattern of relating that they are imposing: we feel 
provoked and persecuted and we can become rejecting, hostile and abusive.

Reliable assessment of risk is therefore based primarily on the ability of the worker to perceive and to tolerate unbearable psychic pain, and on an awareness of the complex defensive manoeuvres used, sometimes by the worker as well as the patient, to avoid reality. Failure to understand the unconscious communications of the patient can lead to faulty or inadequate risk assessment and, thereby, to situations in which violence may escalate.

\section{Assessment of potential violence in psychotic states}

The sectioning of a patient under the Mental Health Act 1983 requires consensus among a number of professionals and, where possible, discussion with the patient's closest relatives. However, even these apparent safeguards do not always prevent mistakes in risk assessment. For illustration, I quote a clinical example presented by Lucas (2003). He describes the situation as follows:

'A patient with a previous record of admission in a violent psychotic state was noted by his mother to be deteriorating. He had stopped complying with his medication, he would no longer allow her access to his residence and she noted, through his window, broken dishes in his bedroom. His mother notified the Community Mental Health Nurse (CMHN) but the patient threatened to harm the CMHN if she attempted to visit. The CMHN notified the GP and, as the responsible psychiatric consultant, I was requested to go on a domiciliary visit. The patient was clearly in a guarded and paranoid state, only allowing a limited dialogue in the hallway. I completed my part of a compulsory order. The GP did not visit, as the patient's current residence was some distance from his practice. The ASW [approved social worker] came with another doctor, approved under the act but previously unfamiliar with the patient. The patient was still guarded in manner, refusing access to his room on the grounds that one's privacy should be respected. He described his mother as having a poor understanding of his needs, but agreed that he should not have spoken in the described manner to the CMHN. The patient said to the ASW that he would be visiting his GP that week to collect further medication and would comply with out patient attendance. In such a situation, it was felt that the order could not be completed. It was also suggested by the ASW that the mother might need help to improve her understanding of her son. The next day, following an unprovoked act of violence towards a stranger in the community, the patient was apprehended and then hospitalised' (pp. 35-36).

Lucas discusses this vignette with reference to Bion's (1957) description of two parts of the mind - a non-psychotic part, which is capable of reflective thinking, and a psychotic part, which operates on a primitive level, fuelled by a hatred of psychic reality, evacuating feelings through delusions and hallucinations or by acting out. Typically, patients experiencing such mental dichotomy will present to the world the non-psychotic part, often appearing rational and denying that he or she is ill. Without Bion's model in mind, one may be forced into a position, as occurred in this case, of adopting a moral stance in which a witness (here, the relative) is held to be wrong. This can result in an underestimation of the degree of potential violence. Lucas quotes the findings of Gelder et al (1998), that lack of insight presenting as denial and rationalisation is present in over $90 \%$ of patients with psychotic disorders. As in the case outlined above, it is often the relatives who are aware of the true level of disturbance, but their view may be outweighed if there is an unconsious wish on the part of the professionals involved not to have to face the true violence and severity of the patient's internal state.

Superficially, Lucas's patient was agreeing to cooperate with his treatment by undertaking to see his GP, but it is important to decide whether one is dealing with a transient outburst, as the approved social worker felt, or with the early stages of a more persistent psychotic relapse. In drawing attention to the particular and persistent psychopathology underlying schizophrenia, Bion invites us to consider this as an alternative explanation for the patient's behaviour. A psychoanalytic approach can contribute by offering a view of the patient's mind and of how his or her past dangerous behaviour resides in that mind. Psychoanalytic theories are also useful in the quest to understand why certain patients who have mental disorders appear to have inadequate defences against the discharge of violent impulses. One should not forget that, along with environmental contributing factors, constitutional features can also play a role.

\section{Assessment of potential violence in borderline personality disorder and paraphilia}

The psychoanalytically informed approach is of particular clinical value when dealing with paraphilias and borderline states. Patients with these disorders operate a paradox: they both know something and do not know it. The two attitudes are held simultaneously and yet are apparently reconciled, and an internal world is thereby created in which reality is distorted and misrepresented. The borderline state of mind arises in the attempt to create this false reconciliation between contradictory 
ideas that can no longer be kept separate, and it is when the perverse solution proves inadequate to contain the patient's internal conflict that aggression and violence can erupt.

The psychoanalytic literature considers it appropriate to use the term 'perversion' as a diagnostic designation. Although sometimes considered pejorative, it is useful to retain this word to indicate a particular sexual practice (Doctor, 2003).

Steiner (1985) has used the phrase 'turning a blind eye' for a defence that is characteristic of what is regarded in psychoanalytic thinking as the 'borderline position'. Thus, perverse patients who are not psychotic and are fully capable of observing reality can nevertheless misrepresent to themselves, and consequently live in, an unreal world of fantasy and illusion. Freud (1938) describes disavowal as the blind but seeing eye which is directed both outwards and inwards, so it is not only the things of the external world that are known and not known, but also thoughts and feelings; they are thought and not thought, felt and not felt. In the perversions, disavowal is placed at the centre of the individual's mental life and it characterises his or her whole relationship to the world. In the countertransference one may act out with the patient and join him in his sanctuary to avoid very unpleasant feelings of violence.

These patients do not fly to external reality to escape their minds, nor do they withdraw into an inner world to avoid the fears of the external world. They cannot, because they are terrified of both internal and external reality, and instead they seek refuge in a state of unreality, which characterises all their relationships. This refuge is reinforced by the secret beliefs hidden in perversions - 'a domain or world of fantasy kept free from the exigencies of life, like a kind of reservation' (Freud, 1924).

The sense of sanctuary, of being in a safe place, invokes an idea of being inside something good. The patients we are considering feel that they need their perversions or misrepresentations to maintain their equilibrium and they often come to treatment when for one reason or another their defences are unable to sustain the status quo. For this type of patient, any threat to psychic homoeostasis, for example a blow to a male patient's self-esteem, an assault on his masculinity, an external trauma, or finding himself in a new or an unfamiliar environment, provokes an aggressive reaction.

When we treat paraphilias, we come to recognise a particularly important interrelationship of feelings, ideas and attitudes that stems from very early in life. Glasser (1979) calls this the 'core complex', and it indicates the persistence of a very primitive level of functioning. In male patients, one major component of this is rooted in a deep-seated and pervasive longing for an intense and most intimate closeness to the mother, amounting to a merging, a 'state of oneness', a 'blissful union'. However, such merging carries with it a profound danger: it threatens a permanent loss of self, the disappearance of his existence as a separate independent individual into the object, as if he is being drawn into a black hole in space.

The conflict between the wish to merge and the terror of annihilation almost invariably comes into the therapeutic relationship as an intense, claustrophobic feeling in the consulting room, followed by the patient's flight, often in the form of missed sessions. But the escape to a safe distance brings with it its own danger, namely the anxiety of isolation. Such an isolated state may involve extremely painful affect and may have been a reason why the patient sought treatment in the first place.

The other major component of the core complex is aggression, in which the ego attempts to resolve the vicious circle of dangers and conflicts by the use of sexualisation. Aggression may therefore be converted into sadism, i.e. sexualised aggression. The intention to destroy is converted into a wish to hurt and control. On an unconscious level, the immediate aim of this in a male patient is the preservation of the mother, who is no longer threatened by total destruction, and the safeguarding of the relationship with her. It is only when this process breaks down that sadism may revert to aggression. When sadism shades into sexual crimes and then into crimes of violence, the appreciation of the other person as a separate and real object decreases and can become entirely lost.

I shall turn now to some clinical material that illustrates the interrelationship of perversion and borderline personality, and violence.

\section{Clinical vignette}

Mr A was a 28-year-old married man who had had long-standing problems with his aggression and a history of cross-dressing, with recently emerging fantasies of a transsexual nature.

Violence, he said, was his main problem. It would just burst out at the smallest provocation: he could be driving along feeling quite peaceful, but if a car cut in ahead of him he would instantly be fighting mad. He would chase the car and be ready to assault the driver. He had once been charged with assault, but had not received a jail sentence and he had no history of delinquency. His greatest concern was his violence towards his wife. She was very argumentative, provoking him and inciting him to violence. He had badly beaten her in the past. One of his reasons for seeking treatment was his concern that he might end up killing her.

During the therapy, it emerged that his crossdressing was, in part, a defence against his violent impulses. When he dressed as a woman, which he did in the privacy of his own home, he felt at peace with the world. He experienced a sense of relaxation and 
fulfilment, free of hatred. He believed that his violent temper would be eradicated forever if he were to become a woman. Through cross-dressing he could assume the identity of his own mother and also become the little girl she would always love and nurture. He was enacting a fantasy of perfect intimacy in a situation that was within his own control - he could not lose his 'mother' and he was no longer helplessly at the mercy of his wife's verbal aggression.

\section{Managing risk: the aims of psycho- therapy with violent patients}

How can a forensic psychoanalytic psychotherapist come into the picture and offer another dimension in the risk containment strategy? Minne (2003) discusses various ways in which a psychotherapeutic approach can contribute to the wider network of treatment provided for these patients. If patients are treated directly in a psychotherapeutic setting, this allows an opportunity for close monitoring of their internal state and of the current level of risk that they are presenting. The psychotherapist may also offer supervision to other team members, providing a language and a conceptual framework for thinking about the internal world of patients and for helping to contain the anxieties of the staff. Supervision may take place individually or in a group; informally, or in the more structured setting of ward rounds and case conferences. These complex patients often split the team, at which point it is very valuable to have a way of thinking about the unconscious dynamics that are being stirred up. The aim in all these situations is to improve the awareness of the unconscious processes at work, and this adds an invaluable dimension to risk assessment and management.

Minne discusses the process of psychotherapeutic work with these patients:

'It is one major task of this kind of psychotherapy to enable awareness of the mind and its function to become available to the owner of that mind, the patient. This includes an awareness of who he is, what he has done and the impact of this on his mind and on the minds of others, i.e. making what is unconscious conscious. Often, patients who have carried out serious violent offences demonstrate a high degree of unawareness, regardless of their diagnosis. This can manifest itself in various ways such as denial, disavowal, minimisation and amnesia. This lack of awareness can appear to be necessary for the patient's psychic survival. If they relinquish 'not knowing' they may then become overwhelmed by the knowledge of who they are and what they have done. This can cause massive anxieties about "cracking up" and can lead to psychotic breakdowns (if they are not already manifestly psychiatrically psychotic) and, perhaps, to suicide' (Minne, 2003: p. 66).
Minne points out that the new-found awareness of his (or her) own mind can feel to the patient like a violent assault on his internal world. It can produce a negative reaction: part of the patient's mind may launch an envious attack on the successful union of patient and therapist, leading to denigration and undermining of the therapeutic work.

In such situations, the need for the patient to trust the confidentiality of the therapeutic relationship may conflict with the therapist's need to communicate information to colleagues if there is the potential for dangerous behaviour. Minne suggests that the best option may be to encourage and enable patients themselves to inform other team members about their potential dangerousness. When this is not possible, trust in the therapist will be best preserved if any proposed sharing of information is discussed first with the patient. It might in fact be a relief to the patient to know that someone else is taking responsibility for these disclosures. This can help the patient to feel understood, which in itself may decrease the immediate risk.

Minne summarises what may be gained:

'The hope is to help [patients] gain understanding and, optimistically, some change in their internal worlds. This may mean a change from a more pathologically defended, personality disordered or psychotic presentation to one reminiscent of a PTSD [post-traumatic stress disorder] state in which the patient might initially feel more distressed but would have, hopefully, a healthier internal world. This would be one in which thoughts and feelings about what happened and about their predicament in relation to this could be experienced in mind, without the need to get rid of these through the familiar violent acting out' (p. 77).

\section{Conclusions}

When viewed from a psychoanalytic perspective, even the most apparently insane violence has a meaning in the internal world of the person who commits it. Understanding this meaning and learning from it can contribute substantially to minimising the risks of further dangerous behaviour. One of the objectives of this article is to provide professionals working in this area with a means of approaching the subject with enriched understanding, in the hope that the risks of violence in their patients may be reduced.

\section{References}

Bion, W. R. (1957) Differentiation of the psychotic from the non-psychotic personalities. In Second Thoughts: Selected Papers on Psychoananlysis, pp. 43-46. New York: Jason Aronson.

Buchanan, A. (1999) Risk and dangerousness. Psychological Medicine, 29, 465-473. 
Buchanan, A. \& Leese, M. (2001) Detention of people with dangerous severe personality disorders: a systematic review. Lancet, 358, 1955-1959.

Doctor, R. (2003) The role of violence in perverse psychopathology. In Dangerous Patients: A Psychodynamic Approach to Risk Assessment and Management (ed. R. Doctor). London: Karnac.

Dolan, M. \& Doyle, M. (2000) Violence and risk prediction. Clinical and actuarial measures and the role of the Psychopathy Checklist. British Journal of Psychiatry, 177, 303-311.

Farnham, F. \& James, D. (2001) Dangerousness and dangerous law. Lancet, 358, 1926.

Freud, S. (1924) Neurosis and psychosis. Reprinted (19531974 ) in the Standard Edition of the Complete Works of Sigmund Freud (trans. \& ed. J. Strachey), vol. 19, pp. 152204. London: Hogarth Press.

Freud, S. (1938) An outline of psychoanalysis. Reprinted (1953-1974) in the Standard Edition of the Complete Works of Sigmund Freud (trans. \& ed. J. Strachey), vol. 23, pp. 195-204. London: Hogarth Press.

Gelder, M., Gath, D., Mayou, R., et al (1998) Oxford Textbook of Psychiatry (3rd edn). Oxford: Oxford University Press

Glasser, M. (1979) Some aspects of the role of aggression in the perversions. In Sexual Deviation (ed. I. Rosen). Oxford: Oxford University Press.

Hinshelwood, R. D. (1999) The difficult patient. The role of 'scientific psychiatry' in understanding patients with chronic schizophrenia or severe personality disorder. British Journal of Psychiatry, 174, 187-190.

Lucas, R. (2003) Risk assessment in general psychiatry - a psychoanalytic perspective. In Dangerous Patients: $A$ Psychodynamic Approach to Risk Assessment and Management (ed. R. Doctor) London: Karnac.

Minne, C. (2003) A psychoanalytic aspect to the risk containment of dangerous patients treated in high security hospitals. In Dangerous Patients: A Psychodynamic Approach to Risk Assessment and Management (ed. R. Doctor) London: Karnac.

Mullen, P. (1999) Dangerous people with severe personality disorder. British proposals for managing them are glaringly wrong - and unethical. BMJ, 319, 1146-1147.

Steiner, J. (1985) Turning a blind eye: the cover-up for Oedipus. International Journal of Psychoanalysis, 63, 161172.

\section{Multiple choice questions}

1 As regards the assessment of risk in psychotic patients:

a it is important to be aware of the psychotic and nonpsychotic parts of the mind

b the patients can present in a non-psychotic part of the mind, appearing rational and denying their illness

c Gelder noted that lack of insight presenting as denial and rationalisation is present in over $90 \%$ of patients with psychotic disorders

$\mathrm{d}$ it is not important to decide whether one is dealing with a transient outburst or with early stages of a more persistent psychotic relapse

e relatives' views of the patient's state of mind are often ignored or minimised

2 As regards countertransference in patients with psychosis:

a it is an important tool in the actuarial method of risk assessment

b when treating these patients, our instinct is to protect ourselves by retreating emotionally into what Hinshelwood calls a 'scientific attitude' c the 'scientific attitude' or depersonalisation may be invited and encouraged by the patient's removal from the world and ordinary human rapport

d when it is unconscious it can cause destructive acting out by staff

e it is to be avoided.

3 As regards the assessment of risk in paraphilia or borderline personalities:

a this involves the awareness of a defence described by Jung as 'disavowal'

$\mathrm{b}$ in 'disavowal', the patient holds simultaneously, and apparently reconciles, two contradictory attitudes, in which reality is distorted and misrepresented

c if the patient's perverse solution to dealing with this false reconciliation proves inadequate to contain the internal conflict, violence can erupt

$\mathrm{d}$ the 'core complex' involves two components: aggression and longing for intimacy

e sadism is sexualised aggression.

4 As regards transference and countertransference in the paraphilias or borderline personality:

a countertransference can be very unpleasant, including feelings of being manipulated and provoked

b countertransference can make clinicians hostile, rejecting and abusive towards the patient

c countertransference can make clinicians act out with their patients, collaborating in their misrepresentation of reality to avoid unpleasant feelings of violence

$\mathrm{d}$ countertransference is a feeling attributed to the patient

e transference is the feeling the patient feels towards the doctor.

5 In the management of violent patients using psychodynamic therapy:

a the psychotherapist's major task is to make the patients aware of who they are, what they have done, and how their own minds function

b patients who have carried out serious acts of violence demonstrate a high degree of self-awareness

c a lack of self-awareness may manifest itself in denial, disavowal and/or minimisation

$\mathrm{d}$ if patients relinquish 'not knowing' they may be overwhelmed by their feelings, which can lead to psychotic breakdown

e the mental distress initially felt by some patients when they gain understanding of their minds is often an improvement on their previous pathological states, particularly as it might be accompanied by a healthy inner world.

\section{MCQ answers}

\begin{tabular}{|c|c|c|c|}
\hline 1 & 2 & 3 & 4 \\
\hline $\mathrm{T}$ & a F & a $F$ & a $\mathrm{T}$ \\
\hline $\mathrm{T}$ & b $\mathrm{T}$ & b $\mathrm{T}$ & $\mathrm{b} T$ \\
\hline $\mathrm{T}$ & c $\mathrm{T}$ & c $\mathrm{T}$ & c $\mathrm{T}$ \\
\hline $\mathrm{F}$ & $\mathrm{d} T$ & $\mathrm{~d} T$ & $\mathrm{~d} F$ \\
\hline $\mathrm{T}$ & e $F$ & e $\mathrm{T}$ & e $\mathrm{T}$ \\
\hline
\end{tabular}

